\title{
PROGRESSO TEMPORAL E CONTROLE DA ANTRACNOSE EM BANANA NO SEMIÁRIDO NORTE MINEIRO ${ }^{1}$
}

\author{
LAIS MAIA E SILVA², MARIANNE GONÇALVES BARBOSA3, \\ MARTIELLE BATISTA FERNANDES ${ }^{4}$, REGINA CÁSSIA FERREIRA RIBEIRO ${ }^{5}$, \\ EDSON HIYDU MIZOBUTSI ${ }^{5}$
}

RESUMO - A antracnose é uma das principais doenças pós-colheita em bananas. O trabalho teve como objetivos avaliar, durante dez meses, a intensidade da antracnose e o efeito da lavagem e da sanitização das frutas no controle da doença em pós-colheita de bananas. O experimento foi realizado de setembro de 2013 a junho de 2014. As coletas dos frutos foram realizadas, mensalmente, em cinco propriedades comerciais localizadas nos municípios de Jaíba, Janaúba e Nova Porteirinha, cultivadas com banana 'Prata-Anã'. As pencas foram subdivididas em buquês de três frutos, e o delineamento experimental foi o inteiramente casualizado, em esquema fatorial e submetidos aos tratamentos: frutos sem a realização da lavagem (testemunha); frutos lavados na propriedade; frutos lavados no laboratório com hipoclorito de sódio a 2\%; frutos lavados no laboratório com hipoclorito de sódio a $2 \%$ seguido de aplicação com fungicida Imazalil. As avaliações foram realizadas em 10 épocas, e os tratamentos, repetidos cinco vezes. Calculou-se área abaixo da curva de progresso da intensidade (AACPI) e a área abaixo da curva de progresso da severidade (AACPS). Os resultados obtidos foram submetidos à análise de variância, e as médias comparadas através do teste de Scott-Knott, a 5\% de probabilidade. A maior intensidade de antracnose em bananas no norte de Minas ocorre nos meses de novembro de 2013 a março de 2014. A menor intensidade ocorre nos meses de setembro e outubro de 2013, e abril a junho de 2014. Nos meses de novembro a março, época de maior intensidade de doença, a lavagem dos frutos com detergente neutro e hipoclorito de sódio a $2 \%$, seguida de aplicação do fungicida Imazalil é a técnica mais eficiente de controle. A lavagem dos frutos, apenas com detergente neutro, pode favorecer o aparecimento de antracnose, pela degradação da cutícula.

Termos para indexação: Colletotrichum musae, manejo, incidência, severidade, pós-colheita.

\section{TEMPORAL PROGRESS AND CONTROL OF ANTHRACNOSE ON BANANA IN SEMIARID IN THE NORTH OF MINAS GERAIS}

\begin{abstract}
Anthracnose is one of the major post harvest diseases of bananas. The study aimed to evaluate for ten months the intensity of the anthracnose and the effect of washing and sanitizing of the fruits in the disease control on the post harvest of bananas. The experiment was conducted from September 2013 to June 2014. The samplings of the fruits were held monthly in five commercial properties located in the cities of Jaíba, Janaúba and Nova Porteirinha, cultivated with banana "Prata-Anã". The bunch of bananas were subdivided into bouquets of three fruits, the experimental design was entirely randomized in factorial scheme and subjected to the treatments: fruits without the realization of the washing (control); fruits washed in the property; fruits washed in the laboratory with sodium hypochlorite at $2 \%$; fruits washed in the laboratory with sodium hypochlorite followed by $2 \%$ Imazalil fungicide application. The evaluations were performed in 10 seasons, and the treatments replicated five times. It was calculated the area below the intensity progress curve (ABIPC) and the area below the severity progress curve (ABSPC). The results obtained were subjected to analysis of variance and average compared by the Scott-Knott test at $5 \%$ of probability. The highest intensity of anthracnose on bananas in North of Minas Gerais occurred in the months of November 2013 to March 2014. The lower intensity occurred in the months of September and October 2013 and from April to June 2014. In the months from November to March, period of higher intensity of the disease, the washing of the fruits with neutral detergent and sodium hypochlorite at $2 \%$ followed by application of Imazalil fungicide is the most efficient control technique. Washing of fruit, only with neutral detergent may increase the incidence of anthracnose, a deterioration of the cuticle.
\end{abstract}

Index terms: Colletotrichum musae, management, incidence, severity, post harvest.

${ }^{1}$ (Trabalho 299-14). Recebido em: 17-11-2014. Aceito para publicação em: 07-10-2015.

${ }^{2}$ Mestre em Produção Vegetal no Semiárido/UNIMONTES. E-mail: laismaiak@hotmail.com

${ }^{3}$ Mestranda no curso de Produção Vegetal no Semiárido/UNIMONTES.E-mail: marianneagronomia@yahoo.com.br

${ }^{4}$ Doutoranda no curso de Produção Vegetal no Semiárido/UNIMONTES.E-mail: martiellefernandes@hotmail.com

${ }^{5}$ Eng $^{\circ}$ Agr. Dsc. Profs. Depto. Ciências Agrárias. UNIMONTES. Bolsistas da FAPEMIG. Janaúba- MG. E-mails: regina.ribeiro@ unimontes.br, edson.mizobutsi@unimontes.br 


\section{INTRODUÇÃO}

O Brasil é o quinto maior produtor mundial de bananas, destacando-se nos primeiros lugares o Equador, Filipinas, China e Índia, respectivamente (FAO, 2014). Apesar do Brasil estar bem colocado no ranking, a cadeia produtiva de banana enfrenta sérios problemas de perdas, principalmente na fase de pós-colheita e na comercialização (BASTOS e ALBUQUERQUE, 2004; MAIA et al., 2008). Essas perdas se devem a fatores físicos, fisiológicos e microbiológicos. Dentre os fatores microbiológicos, os fungos são responsáveis pela maioria das doenças que afetam essa fruta (PESSOA e OLIVEIRA, 2006; MAIA et al., 2008).

O fungo Colletotrichum musae (Berk \& Curt.) Von Arx. é o agente causal da antracnose, que é uma das principais doenças pós-colheita em banana, levando a perdas significativas de até $40 \%$ da produção. A infecção causada por C. musae inicia-se, no campo, em frutos verdes, e o desenvolvimento da doença ocorre durante o amadurecimento, na forma de pequenas lesões, podendo coalescer, formando grandes áreas necróticas e deprimidas (PESSOA e OLIVEIRA, 2006; NEGREIROS et al., 2013). Em condições favoráveis, sob alta umidade, os frutos cobrem-se de frutificações de coloração rosa a salmão, onde os acérvulos adquirem uma coloração acinzentada (CORDEIRO et al., 2005).

Os conídios são produzidos em restos culturais em condições de alta umidade e são dispersos por meio da chuva, do vento e por insetos (PLOETZ et al., 2003). Na presença de água livre, germinam entre 4 e 24 horas e formam apressório. A penetração ocorre de 24 a 48 horas, provocando uma reação de hipersensibilidade nas células adjacentes da epiderme, que acumulam fitoalexinas e tornam a infecção latente até a maturação, a infecção também pode ocorrer por meio de ferimentos (JEGER et al., 1995).

Os fatores ambientais estão envolvidos diretamente na incidência e severidade da doença, uma vez que influenciam nas várias fases do ciclo de vida do patógeno e também no desenvolvimento do hospedeiro, sendo importante para a infecção fitopatogênica (MAFIA et al., 2011; OLIVEIRA et al., 2011).

Estudos fisiológicos demonstram que a faixa de temperatura ótima para a germinação dos conídios e o crescimento micelial de C. musae encontra-se entre $27^{\circ} \mathrm{C}$ e $30^{\circ} \mathrm{C}$ (GOOS e TSCHIRSCH, 1962; COUTO e MENEZES, 2004). Condições de alta umidade relativa favorecem o desenvolvimento do $C$. musae, sendo um fator importante para a esporulação
(VALE e ZAMBOLIM, 1997).

O monitoramento da intensidade da doença é de grande importância, pois permite conhecer as épocas críticas de ocorrência, a identificação dos níveis de dano econômico (VIEIRA JUNIOR et al., 2008), para nessas épocas de maior intensidade, iniciar o controle da antracnose em pós-colheita.

Na região Norte de Minas, as pesquisas sobre o progresso temporal da antracnose são, praticamente, inexistentes. Deste modo, o trabalho teve como objetivos avaliar, durante dez meses, a intensidade da antracnose e o efeito da lavagem e sanitização das frutas no controle de antracnose em banana 'Prata-Anã' cultivada em propriedades localizadas no semiárido norte mineiro nos municípios de Jaíba, Janaúba e Nova Porteirinha.

\section{MATERIAL E MÉTODOS}

O estudo foi realizado no período de setembro de 2013 a junho de 2014. As coletas dos frutos foram realizadas, mensalmente, em propriedades comerciais, cultivadas com banana 'Prata-Anã', nos municípios de Jaíba, Janaúba e Nova Porteirinha. A classificação do clima da região, segundo Koppen, é Aw, caracterizado por chuvas concentradas no verão, e seco nos meses do inverno.

Foram amostradas duas propriedades no município de Jaíba; a propriedade 01, localizada à S $15^{\circ} 12^{\prime} 46^{\prime \prime}$ e W $3^{\circ} 48^{\prime} 36^{\prime \prime}$, altitude de $473 \mathrm{~m}$ e abastecimento de água realizado por canais de irrigação do Projeto Jaíba, e a propriedade 02, localizada à S $15^{\circ} 16^{\prime} 39^{\prime}$ ' e W $43^{\circ} 44^{\prime} 26^{\prime}$ ", altitude de $477 \mathrm{~m}$, e o abastecimento de água feito por poço tubular.

Outras duas propriedades foram amostradas no município de Janaúba, sendo a 03 , localizada à $\mathrm{S} 15^{\circ} 43^{\prime}$ ' " e W $43^{\circ} 19^{\prime} 15^{\prime \prime}$ e altitude de $522 \mathrm{~m}$, e a 04 , localizada à S $15^{\circ} 43^{\prime} 40,4$ " e W $43^{\circ} 18^{\prime} 29^{\prime \prime}$ e altitude de $515 \mathrm{~m}$, respectivamente. Já, a propriedade 05 foi amostrada no município de Nova Porteirinha, localizada à S $15^{\circ} 43^{\prime} 20^{\prime \prime}$ e W $43^{\circ} 16^{\prime} 55^{\prime}$ " e altitude de $517 \mathrm{~m}$. O abastecimento de água das propriedades 03, 04 e 05 é feito por canais de irrigação do Projeto Gorutuba.

As propriedades têm diferentes tipos de manejo. A propriedade 01 dispõe de um cultivo tecnificado, onde os cachos são transportados por cabos aéreos até o galpão de beneficiamento. Neste galpão, as bananas são lavadas em tanques de água contendo detergente neutro e hipoclorito de sódio a $2 \%$. Já as demais propriedades contam com um cultivo tradicional, onde os cachos são transportados por funcionários para um local 
no bananal, onde se cobre o chão com folhas de bananeira. Rotineiramente, as bananas são lavadas com detergente neutro em caixas de água de polietileno.

Os cachos de banana 'Prata-Anã' foram colhidos em estádio pré-climatérico ou estádio de maturação 2 (frutos verdes com traços amarelos), de acordo com escala de Von Loesecke (PBMH e PIF, 2006). Em seguida, os cachos foram despencados e selecionadas as pencas centrais, visando a uma maior uniformidade dos frutos durante a maturação em pós-colheita. Parte destes frutos foram lavados na propriedade onde se realizou a coleta. Em seguida, as pencas foram acondicionadas em caixas plásticas previamente lavadas e sanitizadas, recobertas com papelão para evitar danos gerados por incidência solar, abrasão e choque mecânico. Essas pencas foram encaminhadas ao Laboratório de Patologia Pós-colheita da Unimontes, campus de Janaúba. Ao chegar ao laboratório, as pencas foram subdivididas em buquês de três frutos.

O delineamento experimental utilizado foi o inteiramente casualizado, em esquema fatorial $4 \mathrm{x}$ 10 (4 tratamentos x 10 épocas de avaliações) com cinco repetições, contendo cada uma um buque de três frutos.

Os buquês foram submetidos aos seguintes tratamentos: frutos sem a realização da lavagem (testemunha); frutos lavados na propriedade; frutos lavados no laboratório com detergente neutro e hipoclorito de sódio a $2 \%$; frutos lavados no laboratório com detergente neutro e hipoclorito de sódio a $2 \%$ e seguido de imersão em calda com fungicida Imazalil (Magnate $\left.{ }^{\circledR}\right)$ na concentração de $2 \mathrm{~mL} . \mathrm{L}^{-1}$, posteriormente colocados em bandejas de poliestireno expandido, armazenado em câmara de refrigeração a $25 \pm 1^{\circ} \mathrm{C}$ e $80 \pm 5 \%$ de umidade relativa.

A avaliação da intensidade de doença foi realizada após os frutos atingirem o estádio de maturação 6 (frutos com coloração de casca totalmente amarela), de acordo com escala de maturação de Von Loesecke (PBMH e PIF, 2006). Nesta fase, estimou-se a incidência e severidade. A incidência foi obtida por número de frutos afetados por repetição, sendo esses valores expressos em porcentagem por tratamento. Para a variável severidade foi adotada a escala diagramática desenvolvida por Moraes et al. (2008) com variação de severidade da doença de 0,5 a $64 \%$. Com os resultados de incidência e severidade foram construídas curvas de progresso de doença e calculada a Área Abaixo da Curva de Progresso de Incidência (AACPI) e a Área Abaixo da Curva de Progresso de Severidade (AACPS), conforme a fórmula de Shaney e Finney (1977).
Os resultados obtidos da AACPI, AACPS e de incidência e severidade foram submetidos à análise de variância e as médias comparadas pelo teste de Scott-Knott a $5 \%$ de probabilidade. As análises estatísticas foram efetuadas com uso do software estatístico SISVAR (FERREIRA, 2011).

Os dados meteorológicos mensais de temperatura média, umidade relativa do ar e precipitação pluviométrica total dos meses avaliados foram obtidos da estação de Jaíba/MG (S $15^{\circ} 05^{\prime}$, W $44^{\circ} 00^{\prime} 460 \mathrm{~m}$ ) e de Janaúba/MG (S $15^{\circ} 48^{\prime}$, W $\left.43^{\circ} 17^{\prime} 516 \mathrm{~m}\right)$, pertencentes ao Instituto Nacional de Meteorologia - INMET (Figura 1).

\section{RESULTADOS E DISCUSSÃO}

Em todas as propriedades, menor valor de AACPI $(p<0,05)$ foi observado quando se adotou a lavagem dos frutos com hipoclorito de sódio a $2 \%$ seguida da aplicação do fungicida. A redução da AACPI da antracnose nos frutos das propriedades 01, $02,03,04$ e 05 foi de 48,49\%, 48,64\%, 32,65\%, $42,92 \%$ e $34,44 \%$, respectivamente, em relação à testemunha (Tabela 1).

Com relação à AACPS da antracnose na propriedade 01 , verificou-se redução significativa da doença de 53,96\% quando os frutos foram lavados nas propriedades e de $78,86 \%$ quando lavados com hipoclorito de sódio a $2 \%$ com aplicação do fungicida, em relação à testemunha. Na propriedade 02 , o tratamento com frutos lavados com hipoclorito de sódio a $2 \%$ não apresentou redução do valor de AACPS da doença, fato semelhante ocorreu na propriedade 03, quando os frutos foram lavados na propriedade e também quando foram lavados com hipoclorito de sódio a 2\% (Tabela 2). Estes resultados podem estar relacionados ao fato de que, nestes tratamentos, os frutos foram lavados com detergente neutro. Este apresenta capacidade de degradar a cutícula, deixando o fruto propício à infecção. A cutícula é composta por cutina e ceras, sendo uma barreira eficiente contra a entrada da maioria dos patógenos que colonizam a superfície (STANGARLIN, 2011). Dependendo da espessura ou da densidade dessa camada cuticular, as plantas podem ser mais ou menos resistentes (REINAPINTO e YEPHREMOV, 2009).

Analisando as propriedades 04 e 05 , observase que a lavagem dos frutos, seguida de aplicação de fungicida, proporcionou redução de $87,46 \%$ e $81,22 \%$ da AACPS, respectivamente, quando comparado à testemunha (TABELA 2). Negreiros et al. (2013), utilizando o fungicida tiabendazol no controle da antracnose em pós-colheita de banana 
'Prata', constataram eficiência na redução da severidade da doença até 16 dias após os frutos terem sido armazenados $21 \pm 1^{\circ} \mathrm{C}$ e $80-90 \%$ de umidade relativa.

Verificou-se interação significativa entre as épocas de avaliação e os diferentes tratamentos nas propriedades 01, 02 e 04 quando avaliada a incidência. De forma geral, as médias de incidência foram menores nos meses de setembro a outubro e de maio a junho. Em contrapartida, nos meses de novembro a março, foram observados os maiores índices de doença. Em geral, neste período, o tratamento mais eficiente para a redução de incidência da doença foi à lavagem dos frutos com hipoclorito de sódio a $2 \%$ com aplicação de fungicida.

Analisando a incidência média de antracnose em bananas coletadas em diferentes áreas e épocas do ano, verificou-se, na propriedade 01 , uma redução de $73,4 \%$ em novembro, $33,2 \%$ em fevereiro e $80,2 \%$ em março, em relação à testemunha, quando utilizado o tratamento lavagem dos frutos com hipoclorito de sódio a $2 \%$ com aplicação de fungicida. Nos meses de maio e junho, todos os tratamentos reduziram, significativamente, a incidência da doença quando comparado com a testemunha. Em relação à incidência da antracnose ao longo dos meses de avaliação, observa-se que houve uma tendência de maiores índices da doença nos meses de novembro a março (Figura 2).

Na propriedade 02, não houve incidência da doença nos meses de outubro, novembro, abril e junho e houve redução de 75,25\% e 76,91\% nos meses de janeiro e fevereiro, respectivamente, quando utilizado o tratamento de lavagem dos frutos com hipoclorito de sódio a $2 \%$ com aplicação de fungicida, comparado à testemunha. $\mathrm{O}$ tratamento em que os frutos foram lavados na propriedade teve comportamento semelhante à testemunha, apresentando maior desenvolvimento da doença nos meses de outubro a março. Já no tratamento onde os frutos foram lavados no laboratório, esse fato foi observado nos meses de dezembro a fevereiro.

Verifica-se que, na propriedade 04, somente o tratamento de lavagem dos frutos com hipoclorito de sódio a $2 \%$ com aplicação de fungicida resultou na diminuição significativa da incidência da antracnose quando comparado à testemunha em 86,6\%, 53,2\%, $89 \%$ e $70,6 \%$, nos meses de novembro, dezembro, março e junho, respectivamente.

Para as propriedades 03 e 05 , constatou-se efeito significativo, independente dos fatores épocas de avaliação e diferentes tratamentos, para a variável incidência. Nas duas propriedades, independente das épocas de avaliação, o tratamento de lavagem dos frutos com hipoclorito de sódio a $2 \%$ e a aplicação de fungicida proporcionaram valores de incidência inferiores aos demais tratamentos. Observa-se que, na propriedade 03 , os meses que proporcionaram o maior desenvolvimento da doença foram dezembro e janeiro e, na propriedade 05 , no período de novembro a fevereiro.

Neste período que houve os maiores índices da doença de novembro a março em média em todas as propriedades; a umidade relativa, precipitação e temperatura estavam em média $66,6 \%, 118,99 \mathrm{~mm}$ e $25,71^{\circ} \mathrm{C}$, respectivamente (Figura 1). Embora a umidade relativa do ar não apresentasse condições ideais para o desenvolvimento da doença, Almeida et al. (2003) verificaram, em trabalho realizado em lotes do Projeto de Irrigação Vale do Gorutuba em Janaúba - MG, que há formação de um microclima úmido nos bananais em função da utilização da irrigação e cobertura vegetal do solo, que são condições normais em todos os sistemas de manejo nas propriedades utilizadas.

Para a germinação de esporos de C. musae, é necessária a presença de uma película de água, explicando a maior frequência das espécies nos meses mais quentes e chuvosos do ano. Os conídios de $C$. musae na presença de água germinam entre 4 e 24 horas e infecta os frutos de 24 a 48 horas, portanto, o período de molhamento foliar associado a uma eficiente liberação e dispersão de esporos pode garantir que a infecção ocorra nos frutos, ocorrendo em temperatura ótima de $27^{\circ} \mathrm{C}$; a esporulação também ocorre na mesma temperatura.

Quanto à severidade, foi constatada interação significativa entre os dois fatores, épocas de avaliação e tratamentos, em todas as propriedades. Os menores valores de severidade foram observados nos meses de setembro a outubro para todas as propriedades avaliadas. Nos meses de fevereiro a junho, foram observados menores valores de severidade nas propriedades 03 e 05 . Nas propriedades 02 e 04 houve menor severidade da antracnose nos meses de março a junho, e, em fevereiro a junho, na propriedade 01 (FIGURA 3). Verificou-se que nenhum dos tratamentos não reduziu, significativamente, a severidade quando comparado à testemunha.

O período de maior desenvolvimento da severidade ocorreu em dezembro e janeiro nas propriedades 01,02 e 03 , quando foram utilizados os tratamentos com frutos lavados na propriedade, lavados com hipoclorito de sódio a 2\%; enquanto que, no tratamento com frutos lavados com hipoclorito de sódio a $2 \%$ e aplicação de fungicida, a maior severidade ocorreu apenas em dezembro nas propriedades 02 e 03 . 
No período de dezembro a fevereiro, onde houve o maior desenvolvimento da doença, a ineficiência da lavagem dos frutos na propriedade, possivelmente, provém do aumento das concentrações de inóculo nos tanques de lavagem dos frutos. Segundo Gasparotto et al. (2003), é necessário fazer a renovação periódica da água dos tanques de lavagem, reduzindo, assim, as fontes de inóculo do C. musae.

Com relação à baixa eficiência da lavagem dos frutos com hipoclorito de sódio a 2\%, Fernandes e Bonaldo (2011) também não obtiveram eficiência no controle da antracnose em pós-colheita de bananas, com uso de hipoclorito de sódio a $1 \%$.

Nas propriedades 04 e 05 , os maiores índices da doença ocorreram, em média, no mês de dezembro para todos os tratamentos e testemunha, com exceção do tratamento com lavagem dos frutos com hipoclorito de sódio e aplicação de fungicida, onde a época de avaliação não influenciou de forma significativa os resultados.

De maneira geral, observou-se que a lavagem dos frutos com hipoclorito de sódio a $2 \%$ seguida de fungicida apresentou menores valores de AACPI, AACPS. A aplicação do fungicida proporcionou a redução da intensidade da doença em todos os meses de avaliação. A redução ocasionada por este tratamento está relacionada à ação direta sobre o patógeno.

Estes resultados corroboram com os encontrados por Coelho et al. (2010). Estudando o controle pós-colheita da antracnose da banana 'Prata-Anã', os autores verificaram que as bananas inoculadas com C. musae e tratadas com fungicidas apresentaram menor severidade da doença.

Mesmo reduzindo a intensidade da doença, o fungicida não erradicou totalmente o patógeno no período de maior desenvolvimento da doença, embora apresentasse os menores índices de severidade comparados aos demais tratamentos. Isso pode estar relacionado, pelo fato de esses meses estarem propícios ao desenvolvimento do patógeno. A eficiência dos fungicidas no controle das doenças depende da quantidade do inóculo inicial, da profundidade da infecção no hospedeiro, da taxa de crescimento da infecção, da temperatura e umidade e do grau de penetração do produto no tecido hospedeiro (PLOETZ et al., 1994; TONGTHIENG e SANGCHOTE, 1994).

Dentre as condições climáticas, a precipitação e umidade relativa foram as que mais interferiram no surgimento da antracnose, possivelmente relacionado com a disponibilidade de água na região. A água é essencial no desenvolvimento do fungo C. musae, uma vez que os conídios são liberados e distribuídos apenas quando os acérvulos estão molhados e germinam apenas na presença de água livre ou quando a umidade relativa do ar é bastante elevada (em torno de 100\%). Geralmente, são disseminados por ventos, respingos e chuvas fortes (MENEZES, 2002; AGRIOS, 2005). Condições estas que foram observadas nos meses de novembro a março.

Em trabalho realizado por Pérez e Vidal (2002), ficou demonstrado que ocorre maior porcentagem de conídios germinados de C. musae quando o fungo se encontrava em presença de água livre e em umidade relativa de $100 \%$.

As altas temperaturas também proporcionam o maior desenvolvimento da antracnose. Chillet et al. (2006), avaliando a influência de oscilações de condições climáticas no desenvolvimento de $C$. musae, observaram que a temperatura é um fator importante para esse patossistema, pois influencia o aumento da infecção, acelerando o estádio de maturação do fruto, e as perdas provocadas pelo patógeno.

Em contrapartida, as temperaturas baixas, em torno de $15^{\circ} \mathrm{C}$, e a ausência do período de molhamento proporcionaram o melhor controle no desenvolvimento da antracnose em trabalho realizado por Pessoa et al. (2007), utilizando diferentes temperaturas e período de molhamento de bananas inoculadas com C. musae. 

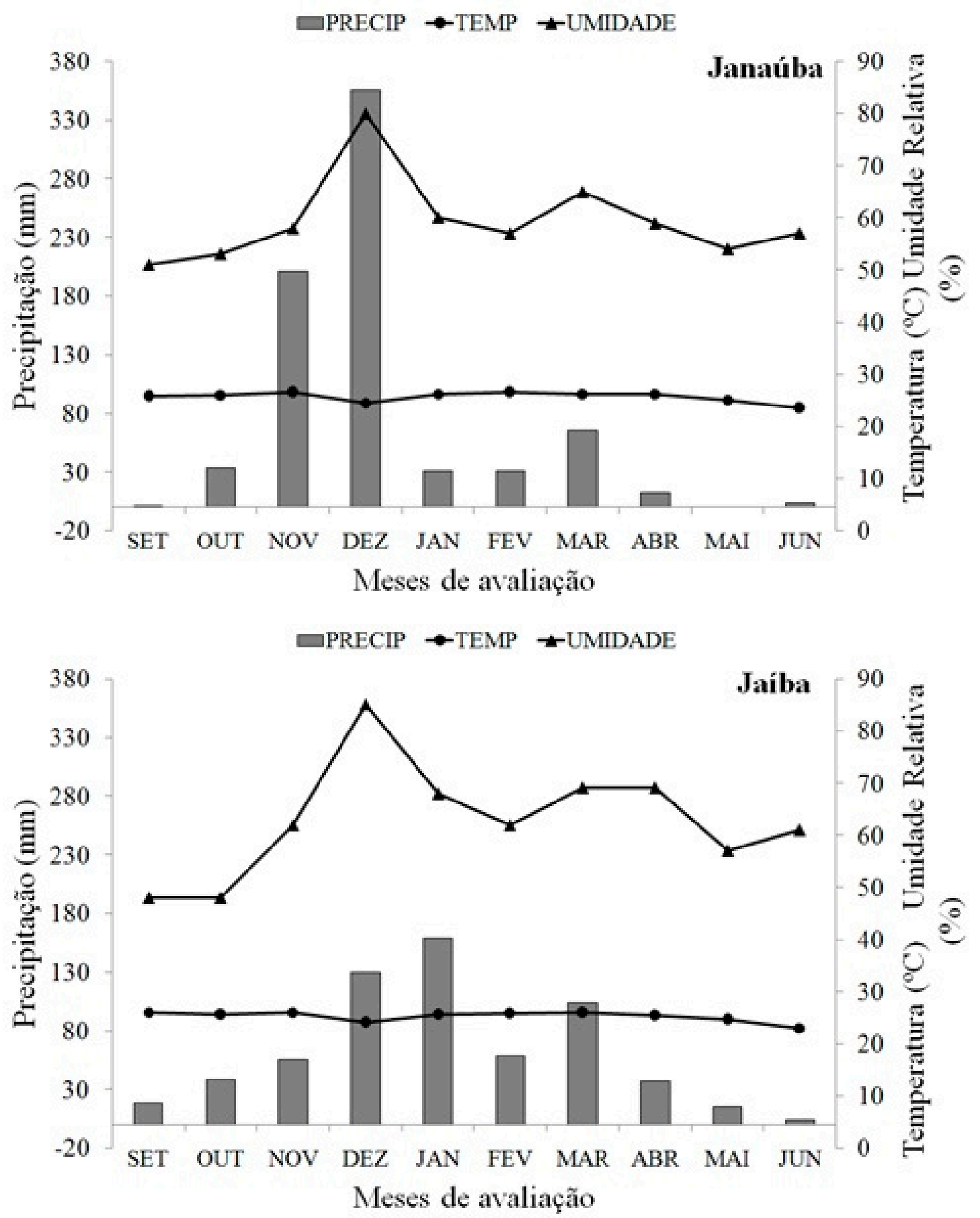

FIGURA 1- Dados meteorológicos registrados para as propriedades comerciais nos meses de setembro a junho, na região de Janaúba-MG e Jaíba-MG, 2013 a 2014. 


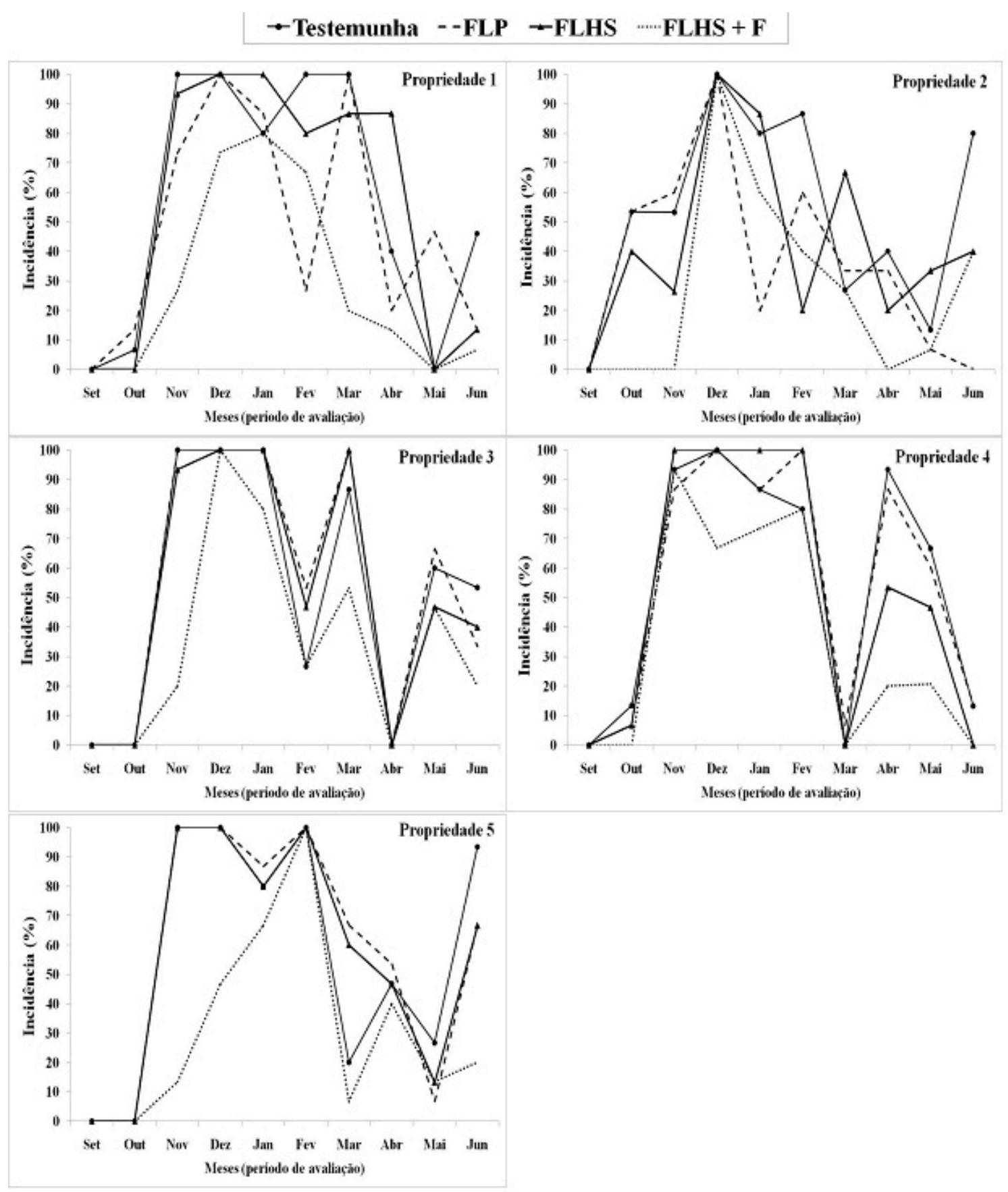

Propriedade 1 e 2 = Jaiba; Propriedade 3 e 4 = Janaúba; Propriedade $5=$ Nova Porteirinha Testemunha $=$ Frutos sem lavagem; FLP $=$ Frutos lavados na propriedade; FLH = Frutos lavados com hipodorito de sódio a $2 \% ; \mathrm{FLH}+\mathrm{F}=$ Frutos lavados com hipoclorito de sódio a $2 \%$ com aplicação de fungicida.

FIGURA 2 - Progresso temporal de incidência da antracnose em banana coletada em diferentes áreas e em diferentes épocas do ano nos municípios de Jaíba e Janaúba - MG, 2013/2014. 


\section{$\rightarrow$ Testemunha - -FLP $\rightarrow$ FLHS $\cdots \cdots$ FLHS + F}

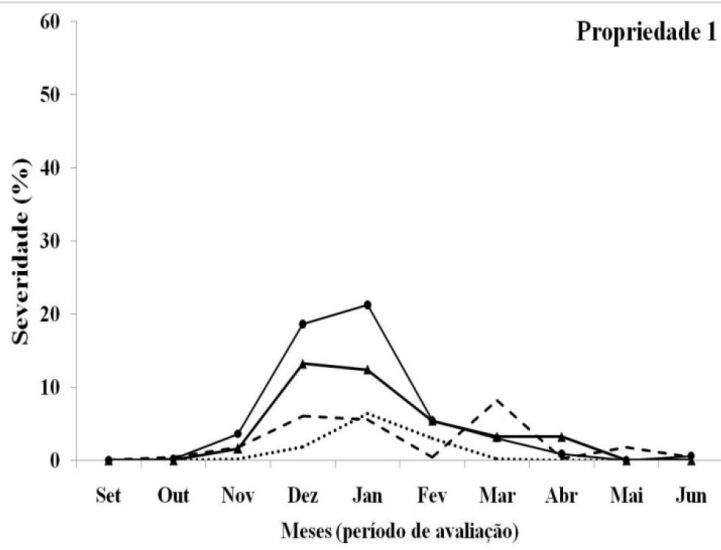

60

Propriedade 2

50

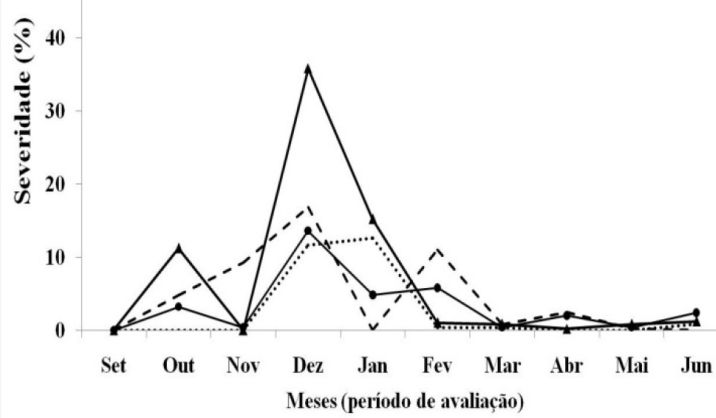

FIGURA 3 - Progresso temporal de severidade da antracnose em bananas coletadas em diferentes áreas e em diferentes épocas do ano nos municípios de Jaíba e Janaúba - MG, 2013/2014. 
TABELA 1- Área Abaixo da Curva de Progresso de Incidência (AACPI) para antracnose em banana de diferentes propriedades e expostas a diferentes tratamentos.

\begin{tabular}{cccccc}
\hline \multirow{2}{*}{ Tratamento* $^{-5}$} & 01 & 02 & 03 & 04 & 05 \\
\cline { 2 - 6 } Testemunha & $550,2 \mathrm{~B}$ & $493,4 \mathrm{C}$ & $499,8 \mathrm{~B}$ & $520,0 \mathrm{~B}$ & $540,0 \mathrm{~B}$ \\
FLP & $473,2 \mathrm{~B}$ & $366,6 \mathrm{~B}$ & $536,6 \mathrm{~B}$ & $533,4 \mathrm{~B}$ & $540,2 \mathrm{~B}$ \\
FLH & $553,6 \mathrm{~B}$ & $413,4 \mathrm{~B}$ & $506,6 \mathrm{~B}$ & $533,2 \mathrm{~B}$ & $506,6 \mathrm{~B}$ \\
FLH+F & $283,4 \mathrm{~A}$ & $253,4 \mathrm{~A}$ & $336,6 \mathrm{~A}$ & $296,8 \mathrm{~A}$ & $354,0 \mathrm{~A}$ \\
\hline CV $(\%)$ & 13,9 & 17,63 & 15,7 & 17,0 & 16,9 \\
\hline
\end{tabular}

$*$ Testemunha $=$ Frutos sem lavagem; FLP $=$ Frutos lavados na propriedade; FLH $=$ Frutos lavados com hipoclorito de sódio a $2 \%$; $\mathrm{FLH}+\mathrm{F}=$ Frutos lavados com hipoclorito de sódio a $2 \%$ com aplicação de fungicida ${ }^{1}$ Médias seguidas de mesma letra, na coluna, não diferem entre si pelo teste Skott-Knott a 5\% de probabilidade.

TABELA 2- Área Abaixo da Curva de Progresso de severidade (AACPS) para antracnose em banana de diferentes áreas e expostas a diferentes tratamentos.

\begin{tabular}{cccccc}
\hline Tratamento* $^{*}$ & \multicolumn{5}{c}{ Propriedade $^{1}$} \\
\cline { 2 - 6 } & 01 & 02 & 03 & 04 & 05 \\
\hline Testemunha & $53,0 \mathrm{~B}$ & $30,6 \mathrm{~A}$ & $41,0 \mathrm{~A}$ & $83,0 \mathrm{~B}$ & $42,6 \mathrm{~B}$ \\
FLP & $24,4 \mathrm{~A}$ & $44,6 \mathrm{~A}$ & $65,2 \mathrm{~B}$ & $66,8 \mathrm{~B}$ & $77,8 \mathrm{~B}$ \\
FLH & $39,2 \mathrm{~B}$ & $65,8 \mathrm{~B}$ & $85,4 \mathrm{~B}$ & $78,6 \mathrm{~B}$ & $63,0 \mathrm{~B}$ \\
FLH+F & $11,2 \mathrm{~A}$ & $24,8 \mathrm{~A}$ & $25,0 \mathrm{~A}$ & $10,4 \mathrm{~A}$ & $8,0 \mathrm{~A}$ \\
\hline CV (\%) & 54,5 & 39,4 & 47,9 & 48,0 & 36,6
\end{tabular}

$*$ Testemunha $=$ Frutos sem lavagem; FLP $=$ Frutos lavados na propriedade; FLH = Frutos lavados com hipoclorito de sódio a $2 \%$; $\mathrm{FLH}+\mathrm{F}=$ Frutos lavados com hipoclorito de sódio a $2 \%$ com aplicação de fungicida. ${ }^{1}$ Médias seguidas de mesma letra, na coluna, não diferem entre si pelo teste Skott-Knott á 5\% de probabilidade

\section{CONCLUSÕES}

A maior intensidade de antracnose em bananas no Norte de Minas ocorre nos meses de novembro a março.

A menor intensidade ocorre nos meses de setembro a outubro e de abril a junho.

Nos meses de novembro a março, época de maior intensidade de doença, a lavagem dos frutos com detergente neutro e hipoclorito de sódio a $2 \%$ seguida de aplicação do fungicida Imazalil é a técnica mais eficiente de controle do fitopatógeno.

\section{AGRADECIMENTOS}

Os autores agradecem à Fundação de Amparo à Pesquisa do Estado de Minas Gerais FAPEMIG, Coordenação de Aperfeiçoamento de Pessoal de Nível Superior - CAPES e Conselho Nacional de Desenvolvimento Científico e Tecnológico - CNPq pelo apoio indispensável para a realização do trabalho.

\section{REFERÊNCIAS}

AGRIOS, G.N. Plant diseases caused by fungi. In: AGRIOS, G.N. Plant Pathology. 5th ed. Amsterdam: Elsevier Academic Press, 2005. p.385-614.

ALMEIDA, C.O.; SOUZA, J.da S.; CORDEIRO, Z.J.M. Aspectos socioeconômicos. In: CORDEIRO, Z.J.M. Banana: produção, aspectos técnicos. Brasília: Embrapa Comunicação para Transferência de Tecnologia, 2000. p.10-11. (Frutas do Brasil, 1).

BASTOS, C.N.; ALBUQUERQUE, P.S.B. Efeito do óleo de Piper aduncum no controle em pós-colheita de Colletotrichum musae em banana. Fitopatologia Brasileira, Brasília, v.29, n.5, p.255-257, 2004.

CHILLET, M.; HUBERT, O.; RIVES, M.J.; LAPEYRE de BELLATRE, L. Effects of the physiological age of bananas on their susceptibility to wound anthracnose due to Colletotrichum musae. Plant Disease, Saint Paul, v.90, n.9, p.1181-1185, 2006. 
COELHO, A.F.S.; DIAS, M.S. de C.; RODRIGUES, M.L.M.; LEA, P.A.M. Controle pós-colheita da antracnose da banana 'Prata anã' tratada com fungicidas e mantida sob refrigeração. Ciência Agrotecnológica, Lavras, v.34, n.4, p.1004-1008, 2010 .

CORDEIRO, Z.J.M.; MATOS, A.P.; KIMATI, H. Doenças da bananeira. In: KIMATI, H. AMORIM, L.; REZENDE, J.A.M.; BERGAMIN FILHO, A.; CAMARGO, L.E.A. (Ed.). Manual de fitopatologia: doenças das plantas cultivadas. 4.ed. São Paulo: Agronômica Ceres, 2005.v.2, p.99-117.

COUTO, E.F.; MENEZES, M. Caracterização fisiomorfológica de isolados de Colletotrichum musae. Fitopatologia Brasileira, Brasília, v.29, n.4, p.406-412, 2004.

FAO - Food and Agriculture Organization of the United Nations. FAOSTAT. Summary of food and agriculture statistics. Disponível em: $<$ http:// faostat.fao.org/site/339/default.aspx $>$. Acesso em: 15 maio 2014.

FERNANDES, S.O.; BONALDO, S.M. Controle de antracnose (Colletotrichum musae) e conservação em pós-colheita de banana 'nanica' no norte de Mato Grosso. Enciclopédia Biosfera, Goiânia, v.7, n.13, p.237-247, 2011.

FERREIRA, D.F. SISVAR: a computer statistical analysis system. Revista Ciência e Agroecologia, Lavras, v.35, n.6, p.1039-1042, 2011.

GASPAROTTO, L.; PEREIRA, J.C.R.; PEREIRA, M.C.N. Manejo integrado de doenças da bananeira. Manaus: Embrapa Amazônia Ocidental, 2003. 6 p. (Circular Técnica, 19).

GOOS, R.D.; TSCHIRSCH, M. Effect of environmental factors on spore germination, spore survival, and growth of Gloeosporium musarum. Mycologia, Lancaster, v.54, p.353-367, 1962.

JEGER, M.J.; EDEN-GREEN S.; THRESH J.M.; JOHANSON A.; WALLER J.M.; BROWN A.E. Banana disease. In: GOWEN, S. (Ed.). Bananas and plantains. London: Chapman \& Hall, 1995. p.317-381.
MAFIA, R.G.; ALFENAS A.C.; LOOS.R.A. Impacto potencial das mudanças climáticas sobre doenças no eucalipto cultura no Brasil. In: GHINI, R.; HAMADA, E.; BETTIOL, W. Impactos das mudanças climáticas sobre doenças de importantes culturas no Brasil. São Paulo: Embrapa Meio Ambiente, 2011. cap.12, p.213-225.

MAIA, V.M.; SALOMÃO, L.C.C.; SIQUEIRA, D.L.; PUSCHMANN, R.; MOTA FILHO, V.J.G.; CECON, P.R. Tipos e intensidade de danos mecânicos em bananas 'Prata Anã' ao longo da cadeia de comercialização. Revista Brasileira de Fruticultura, Jaboticabal, v.30, n.2, p.365-370, 2008.

MENEZES, M. Aspectos biológicos e taxonômicos de espécies do gênero Colletotrichum. Fitopatologia Brasileira, Brasília, v.27, p.523-524, 2002. Suplemento.

MORAES, W.S.; ZAMBOLIM, L.; LIMA, J.D. Quimioterapia de banana 'Prata anã' no controle de podridões pós-colheita. Arquivos do Instituto Biológico, São Paulo, v.75, n.1, p.79-84, 2008.

NEGREIROS, R.J.Z. de. SALOMÃO, L.C.C; PEREIRA, O.L.; CECON, SIQUEIRA, P.R.D.L. de. Controle da antracnose na pós-colheita de bananas 'Prata' com produtos alternativos aos agrotóxicos convencionais. Revista Brasileira de Fruticultura, Jaboticabal, v.35, n.1, p.51-58, 2013

OLIVEIRA, C.A.; SOUZA, E.; POZZA, E.A.; PINTO, J.E.B.P.; BARRETTI, P.B. Efeito de variáveis ambientais, épocas e métodos de plantio na intensidade da seca da haste (Botrytis cinerea) em Hibiscus sabdariffa. Summa Phytopathologica, Botucatu, v.37, n.2, p.101-106, 2011.

PBMH \& PIF - Programa Brasileiro para a Modernização da Horticultura \& Produção Integrada de Frutas.. Normas de classificação de banana. São Paulo: CEAGESP, 2006. (Documentos, 29). Disponível em: <http://www.ceagesp.gov.br/ produtor/classific/fc banana $>$. Acesso em: 15 maio 2014. 
PESSOA, W.R.L.S. et al. OLIVEIRA, S.M.A.; DANTAS, S.A.F.; TAVARES, S.C.C. DE H.; SANTOS, A.M.G. Efeito da temperatura e período de molhamento sobre o desenvolvimento de lesões de Colletotrichum musae em banana. Summa Phytopathologica, Botucatu, v.33, n.2, p.147-151, 2007.

PESSOA, W.R.L.S.; OLIVEIRA, S.M.A. Doenças da banana. In: OLIVEIRA, S.M.A.; TERAO, D.; DANTAS, S.A.F.; TAVARES, S.C.C.H. (Ed.). Patologia pós-colheita: frutas, olerícolas e ornamentais tropicais. Brasília, DF: Embrapa Informação Tecnológica, 2006. p. 539-553.

PLOETZ, R.C. et al. ZENTMYER, G.A; NISHIJIMA, W.T.; ROHRBACH, K.G.; OHR, H.D. Compendium of tropical fruits disease. Minnesota: APS Press, 1994. 88 p.

PLOETZ, R.C.; THOMAS, J.E.; SLABAUGH, W.R. Diseases of banana and plantain. In: PLOETZ, R.C. (Ed.). Diseases of tropical fruit crops. Wallingford: Centre for Agriculture and Biosciences International, 2003. p.73-134.

REINA-PINTO, J.J.; YEPHREMOV, A. Surface lipids and plant defenses. Plant Physiology and Biochemistry, Paris, v.47, n.6, p.540-549, 2009.
STANGARLIN, J.R.; KUHN, O.J.; TOLEDO, M.V.; PORTZ, R L; SCHWANESTRADA, K R F; PASCHOLATI, S F. A defesa vegetal contra fitopatógenos. Scientia Agraria Paranaensis, Acrelandia, v. 10, n. 1, p. 18-46, 2011.

TONGTHIENG, T.; SANGCHOTE, S. Postharvest fruit rot banana caused by Colletotrichum musae (Berk y Curt.) arx. and its control. In: CHAMP, B. R.; HIGHLEY, E.; JOHANSON, G.I. (Eds.). Postharvest handling of tropical fruits. Camberra: ACIAR, 1994. p.462-463.

VALE, F.X.R.; ZAMBOLIM, L. (Ed.). Controle de doenças de plantas: grandes culturas. Viçosa: UFV, 1997. $1132 \mathrm{p}$.

VIEIRA JUNIOR, J.R. FERNANDES, C.F.; RODRIGUES, V.G.S.; BENTES-GAMA, M.M.; SILVA, D.S.G.; FERNANDES, S.R.; DIOCLESIANO, J.M. Avaliação da severidade da ferrugem (Hemileia vastatrix) em cafeeiros (Coffea canephora) cultivados em condições de sombreamento. Porto Velho: Embrapa, 2008. 4 p. (Circular Técnica, 103). 